\title{
THE EFFECT OF DIFFERENT TYPES OF CORE MATERIAL ON THE FLEXURAL BEHAVIOR OF SANDWICH COMPOSITES FOR WIND TURBINE BLADES
}

\author{
Cihan Kaboglu ${ }^{1},{ }^{\star}$, Soraia Pimenta ${ }^{1}$, Andy Morris $^{2}$, John P Dear ${ }^{1}$ \\ Keywords: Composite sandwich structure, failure mode
}

\begin{abstract}
In this study, three differently-configured sandwich structures were manufactured with three different core materials: Balsa wood, Tycor and Polyethylene terephthalate

(PET). Glass-Fibre Reinforced Polymer (GFRP) skins were used to understand the effects of different types of core materials on the flexural behavior of sandwich composites under four point bending (4PB) condition, using digital image correlation (DIC). DIC is one of the most outstanding techniques to understand the mechanical behavior of the structure during the test, thus defining any problematic regions in the structures. The failure mechanisms of the structures were observed by using strain maps of the structures. The results show that the sandwich structure with Balsa wood as a core material has the highest stiffness; however, catastrophic failure appeared in the early stages of the test. The sandwich structure with PET and Tycor exhibited very similar behaviour under load.
\end{abstract}

\section{INTRODUCTION}

Sandwich composites are commonly used in naval, aviation and energy applications [1-4]. The core material used in these composites affects the flexural mechanical behaviour of the structures. Conventionally, Balsa wood is used as the core materials especially wind turbine blades. However, polymeric foams have become more popular for wind turbine applications due to their high strength and high stiffness-to-weight ratio. The increase in demand for polymer foam usage in composite sandwiches has encouraged the polymer foam industry to produce novel foam materials.

Abbadi et al. investigated the effect of the core density and changing foam type on mechanical properties of sandwich structures. Sandwich composites were manufactured with honeycomb core with various densities of 55 $\mathrm{kg} / \mathrm{m}^{3}$ and $82 \mathrm{~kg} / \mathrm{m}^{3}$ of aluminium core and $48 \mathrm{~kg} / \mathrm{m}^{3}$ of aramide fibre core were tested through a $4 \mathrm{~PB}$ test. They concluded that increasing the core density induced increasing of the stiffness of the structures and the load to failure. In addtion, comparing the aramide fibres and aluminium cores, the structures with aluminium cores were more brittle than the ones made of aramide fibres. They also reported that nature of core such as materials, densities and microstructures play a big role on the failure modes of the structures[5].

Gupta and Woldesenbet performed flexural test such as $3 \mathrm{~PB}$ and 4PB tests to understand the influence of changing core density on the flexural properties of the sandwich composites. The sandwich composites were manufactured with using glass-fibre and epoxy as a skin and syntactic foam with various densities: 493, 545, 569, 575 and $650 \mathrm{~kg} / \mathrm{m}^{3}$. It can be said that the density of the core affect the flexural properties of the sandwich composite. However, the microstructure of the foam was more dominant in influencing the flexural property of the sandwich structure than the density of the core material. On the contrary the microstructure did not influence the core shear stress and the skin bending stress, because all the load was on the matrix resin which was used in the foam [6].

Manalo et al. studied on flexural mechanical properties of the noval sandwich composite manufactured with glassfibre reinforced polymer skins and modified phenolic core materials through 4PB tests in flatwise and edgewise. They reported that the sandwich composites were broken abruptly under load in flatwise position. In contrast, in the edgewise

${ }^{1}$ Mechanical Engineering, Imperial College London, London, United Kingdom

${ }^{2}$ Central Technical Organization EDF Energy- Coal, Gas and Renewables, West Burton Power Station, Retford, United Kingdom

*E-mail address: c.kaboglu13@imperial.ac.uk 
position, sudden failure did not appear due to the presence of the fibre composite skin and also the skin increased the ultimate strength of the structures. It can be said that the sandwich composite in flatwise can carry tensile and compressive stress and the sandwich composite in edgewise position can shear [7].

In the literature, generally Polyvinyl chloride (PVC) foam as core materials and glass-fibre reinforcement polymer as skins were investigated. Therefore, in this study three different core materials which are Balsa wood, Tycor and PET core were studied to understand the behaviour of the structure under flexure load.

\section{MATERIALS AND EXPERIMENTS}

Two layers of Bi-axial reinforcement of glass-fibre fabric for top and bottom layers of the skins and four layers of unidirectional glass-fibre fabric for middle layers of the skins epoxy resin for a matrix material were used. The specification of the reinforcement is given in Table 1.

Table 1: DESCRIPTION OF THE REINFORCEMENT OF THE MANUFACTURED SPECIMENS[8]

\begin{tabular}{lllll}
\hline Manufacturer & Reference & Style & $\begin{array}{l}\text { Areal } \\
\text { density } \\
\text { (g/sq.m) }\end{array}$ & $\begin{array}{l}\text { Primary } \\
\text { Fibre } \\
\text { Type }\end{array}$ \\
\hline Ahlstrom & SE1500 & $\begin{array}{l}\text { Biaxial } \\
\text { Fabric }\end{array}$ & 600 & E-glass \\
\cline { 3 - 4 } & & UD & 650 & \\
& & Fabric \\
& & & \\
& & &
\end{tabular}

Three different core materials were used; Balsa wood, Tycor and PET. The specification of the core materials is given in Table 2.

\begin{tabular}{|c|c|c|c|}
\hline $\begin{array}{l}\text { Core } \\
\text { materials }\end{array}$ & Balsa Wood & Tycor & PET \\
\hline $\begin{array}{l}\text { Density } \\
\left(\mathrm{kg} / \mathrm{m}^{3}\right)\end{array}$ & 150 & 180 & 130 \\
\hline $\begin{array}{l}\text { Shear } \\
\text { strength } \\
(\mathrm{MPa})\end{array}$ & 2.6 & 1.7 & 1.3 \\
\hline $\begin{array}{l}\text { Shear } \\
\text { modulus } \\
(\mathrm{MPa})\end{array}$ & 187 & 95 & 30 \\
\hline
\end{tabular}

The configurations of the sandwich composite structures were performed in the study are given in Table 3. 
Journal of Thermal Engineering, Research Article, Vol. 3, No. 2, pp. 1102-1109, April, 2017

Table 3: CONFIGURATIONS OF THE SPECIMENS

\begin{tabular}{|c|c|c|}
\hline Configuration & $\begin{array}{l}\text { Balsa Wood- } \\
\text { Cored }\end{array}$ & Tycor-Cored \\
\hline Skin & $\begin{array}{l}6 \text { layers glas } \\
\text { epoxy matrix }\end{array}$ & fibre (total 3800 gsm) with \\
\hline Core & $\begin{array}{c}\text { Balsa Wood } \\
\text { (19 mm } \\
\text { thick) }\end{array}$ & $\begin{array}{l}\text { Tycor } \\
\text { (12 mm } \\
\text { thick) }\end{array}$ \\
\hline Skin & $\begin{array}{l}6 \text { layers glas } \\
\text { epoxy matrix }\end{array}$ & fibre (total $3800 \mathrm{gsm}$ ) with \\
\hline
\end{tabular}

Flexural bending tests in the condition of 4PB were conducted according to ASTM C393[12] in an Instron testing machine controlled by Bluehill software. The specification of the test rig and set up of the rig are given in Table 4 and Figure 1.

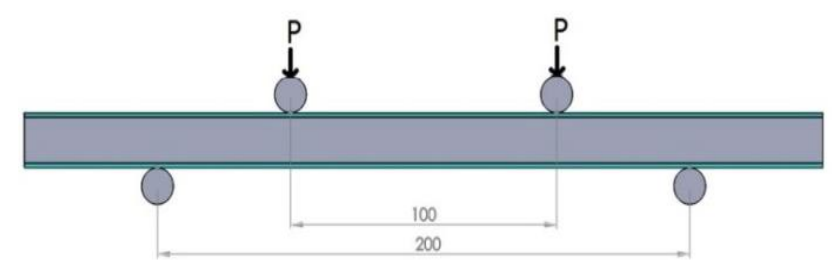

Figure 1: Theoretical set-up of 4PB test

Table 4: SPECIFICATION OF THE TEST RIG

\begin{tabular}{ll}
\hline Span of supporter for the rig & $200 \mathrm{~mm}$ \\
Span of the indentors for the rig & $100 \mathrm{~mm}$ \\
Diameter of supporters and indentors & $12 \mathrm{~mm}$ \\
Velocity of the indentors & $6 \mathrm{~mm} / \mathrm{min}$ \\
\hline
\end{tabular}

To obtain a better understanding of the response of the sandwich structures, Digital Image Correlation (DIC) was used. This technique tracks a domain of points in an image series captured throughout the test, using the first image of the series as a reference. This allows studying the sample surface deformation and all related strains, as shown in Figure 2.
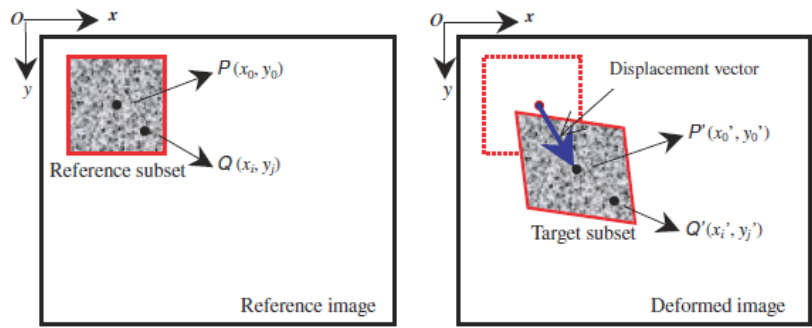

Figure 2: Schematic illustration of a reference image and deformed image in DIC analysis [13] 
A 2D-type analysis was used for the tests, considering displacements in the length-wise $(x)$ and thickness-wise $(y)$ only, hence one of the $x y$ surfaces of each specimen was speckled with spray paint. Images were acquired every 2 seconds during the test with a GOM Aramis 5M camera, and strain maps were analysed using the Aramis software.

Core shear stresses were calculated for each of the samples throughout the test, according to ASTM C 393:

$$
\tau_{\mathrm{c}}=\frac{P}{(d+c) b},
$$

where $\tau_{\mathrm{c}}$ is the core shear stress, $P$ is the applied load, $d$ is the sandwich thickness, $c$ is the core thickness, and $b$ is the sandwich width.

The overall specimen deflections were obtained through an optical extensometer tracking the vertical displacement of the loading and supporting pins. For each specimen, the deflections were shifted by a constant value to ensure a directly proportional relationship with the shear stress within the 300 to $500 \mathrm{kPa}$ range; this was required to discount for the extra compliance provided at the beginning of each test by rubber pads placed between the pins and the surface of the specimen, used to avoid ply damage of the latter.

\section{RESULTS}

The results of the sandwich composites with three different core (Balsa wood, Tycor and PET) under 4PB load are depicted in Figure 3-5. The picture represents shear stress in the core versus crosshead displacement of the specimens and two different strain maps of the specimens considering epsilon $\mathrm{Y}\left(\varepsilon_{\mathrm{y}}\right)$ and epsilon $\mathrm{XY},\left(\varepsilon_{\mathrm{xy}}\right)$.

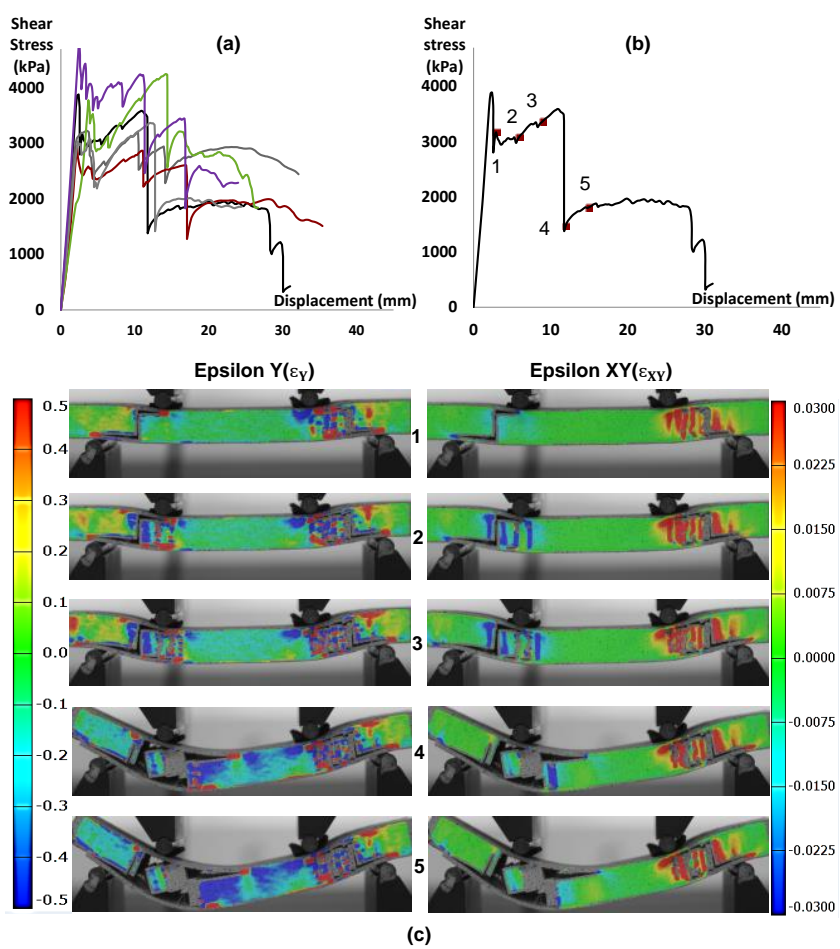

Figure 3: Strain visualization and 4PB test results of Balsa wood-cored sandwich structure: (a) all shear stress- displacement curves of the sample, (b) 4PB test result of the selected sample, (c) Strain visualization for every $5 \mathbf{~ m m}$ of displacement of selected sample. 


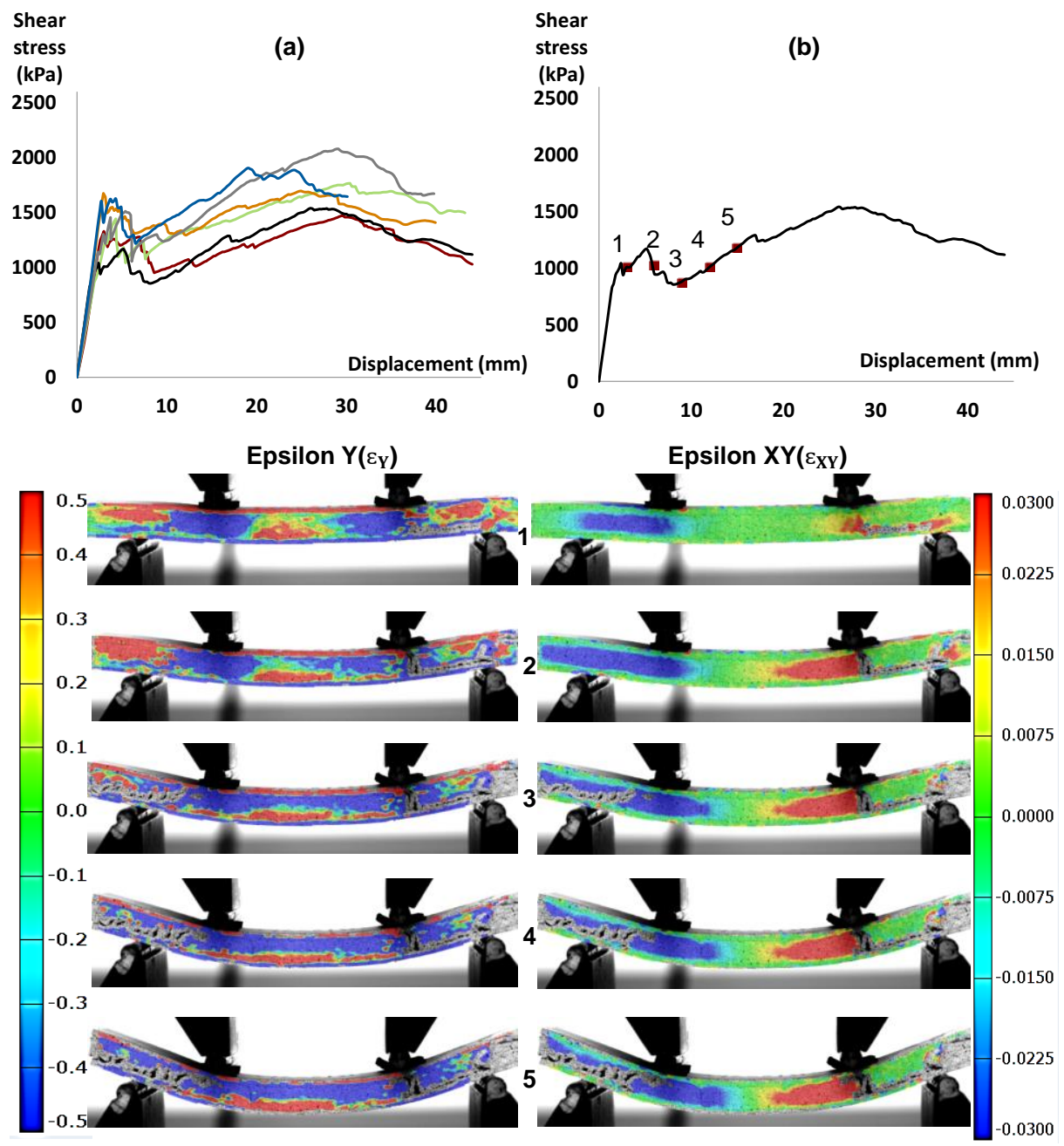

(c)

Figure 4: Strain visualization and 4PB test results of Tycor-cored sandwich structure: (a) all shear stressdisplacement curves of the sample, (b) 4PB test result of the selected sample, (c) Strain visualization for every $5 \mathbf{~ m m}$ of displacement of the selected samples

The results of the Tycor-cored sandwich composite are depicted in Figure 4. Firstly, shear crack appeared and then debonding between the skin and the core followed. There is a small decreasing of shear stress on the graph due to the shear crack.

For the PET-cored sandwich composites, Figure 5 shows that no damage appeared in the specimens until at the displacement of nearly $27 \mathrm{~mm}$. After the point, there is an abrupt decreasing of the shear stress because of the shear crack in the core and deboning between the skin and the core. 

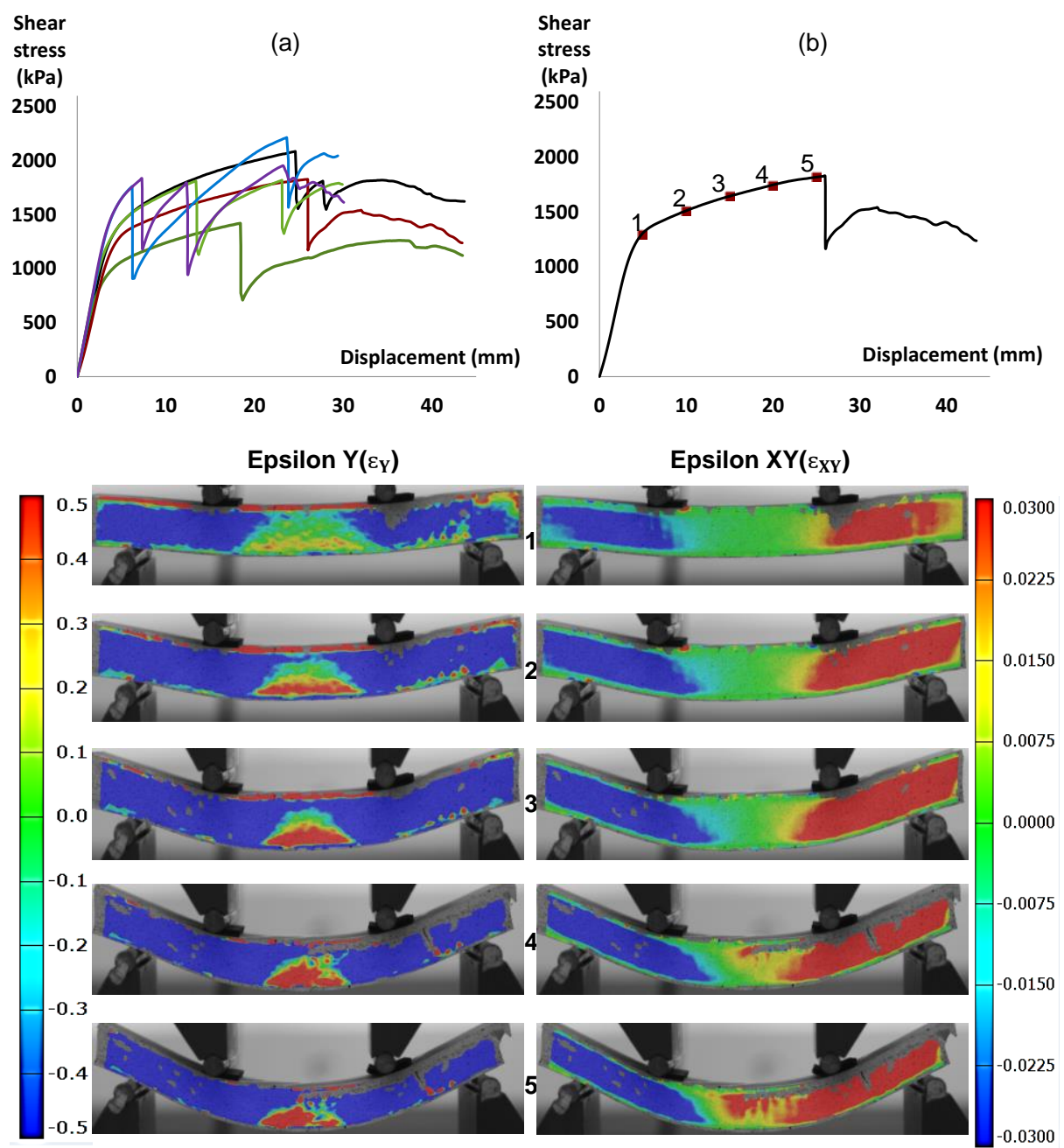

(c)

Figure 5: Strain visualization and 4PB test results of PET-cored sandwich structure: (a) all shear stressdisplacement curves of the sample, (b) 4PB test result of the selected sample, (c) Strain visualization for every $5 \mathrm{~mm}$ of displacement

\section{DISCUSSION}

All comparison between all types of sandwich composites under flexural loading in condition of 4PB is depicted in Figure 6. It can be said that all shear stress versus displacement curves have a shear stress drop at one stage of the experiment. The shear stress drop of the Balsa wood-cored sandwich structure was on the very early stage of the experiment comparing the others. It can be concluded that the sandwich composite which Balsa wood used as a core material showed very brittle behavior than the others. On the other hand the sandwich composite which Balsa wood used as a core material has the highest shear stress and stiffness within the sandwich composites. It can be inferred that the nature of the Balsa wood caused the all behavior of the sandwich composite. 


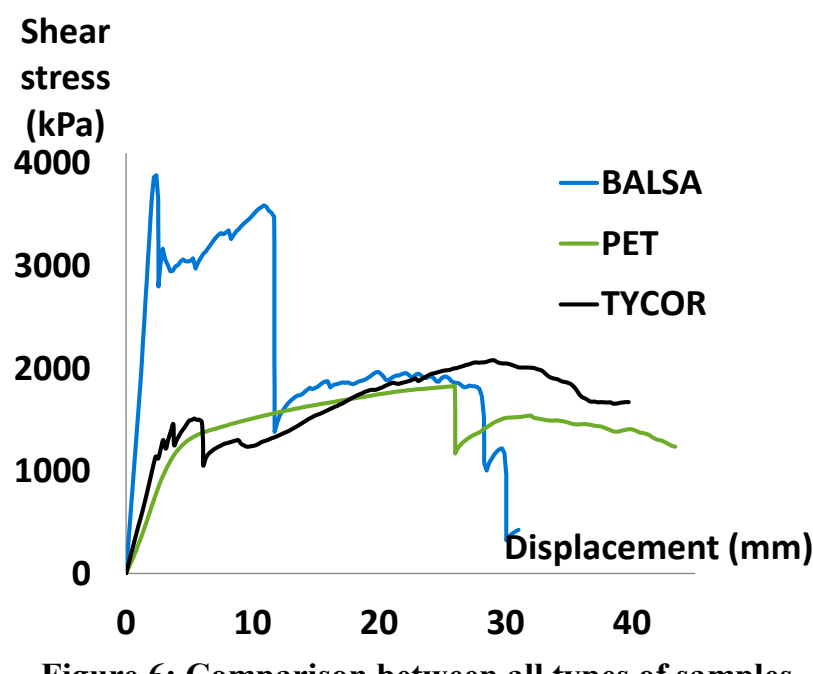

Figure 6: Comparison between all types of samples

From Figure 6,PET can be used as a substitute of Tycor as a core material, when more damage tolerance is needed, because the first failure appeared at the displacement of $27 \mathrm{~mm}$. On the other hand, the sandwich composite with Tycor performed slightly better than sandwich composite with PET in terms of shear strength and stiffness.

From the DIC images of the experiment, shear cracks were observed as a first failure and then debonding between the skin and the core followed the shear crack. Kinked shear cracks appeared on the sandwich composites which were fabricated with Tycor and PET as a core material, while perpendicular shear crack was observed on the sandwich structure which Balsa wood was used as a core material.

\section{CONCLUSIONS}

In the study, three different core materials were used to understand the effect of the changing material on the flexural mechanical properties by performing $4 \mathrm{~PB}$ tests. The following conclusions can be drawn:

- The sandwich composite with Balsa wood has the greatest flexural mechanical properties in terms of shear strength, stiffness, compared to sandwich composites with Tycor and PET.

- Changing core material gives the option to purposely design a sandwich composite depending on requirement of the component.

- The sandwich composite with PET has more damage tolerance than the sandwich composite with Balsa wood and Tycor. That prevents the component or system containing components fabricated with PET as a core material from experiencing catastrophic failure, giving time to repair/replace the component.

- Strain visualization of sandwich samples clearly reveals the shear strain maps during the bending tests, which allows an understanding the effect of different designs on the mechanical properties of sandwich structures.

\section{REFERENCES}

[1] R. Nasirzadeh and A. R. Sabet, "Study of foam density variations in composite sandwich panels under high velocity impact loading," International Journal of Impact Engineering, vol. 63, pp. 129-139, 2014.

[2] A. Rajaneesh, I. Sridhar, and S. Rajendran, "Relative performance of metal and polymeric foam sandwich plates under low velocity impact," International Journal of Impact Engineering, vol. 65, pp. 126-136, 2014.

[3] T. D. Ashwill and J. A. Paquette, "Composite materials for innovative wind turbine blades," Wind Energy Technology Department, Sandia National Laboratories, Albuquerque, NM, vol. 87185, 2008. 
[4] L. Mishnaevsky Jr and O. Favorsky, "Composite materials in wind energy technology," Thermal to Mechanical Energy Conversion: Engines and Requirements, EOLSS Publishers: Oxford, UK, 2011.

[5] A. Abbadi, Y. Koutsawa, A. Carmasol, S. Belouettar, and Z. Azari, "Experimental and numerical characterization of honeycomb sandwich composite panels," Simulation Modelling Practice and Theory, vol. 17, pp. 1533-1547, 2009.

[6] N. Gupta and E. Woldesenbet, "Characterization of Flexural Properties of Syntactic Foam Core Sandwich Composites and Effect of Density Variation," Journal of Composite Materials, vol. 39, pp. 2197-2212, December 1, 20052005.

[7] A. C. Manalo, T. Aravinthan, W. Karunasena, and M. M. Islam, "Flexural behaviour of structural fibre composite sandwich beams in flatwise and edgewise positions," Composite Structures, vol. 92, pp. 984-995, $3 / / 2010$.

[8] (2015, 28/08/2015). Ahlstrom Product Catalogue. Available: http://www.ahlstrom.com/en/Products/

[9] (2014, 25/11/2014). AirexBaltekBanova. Available: http://www.3accorematerials.com/products/airex/

[10] (2015, 28/08/2015). Data Sheet Tycor Fiber Reinforced Cores. Available: http://tycor.milliken.com/Pages/products.aspx

[11] (2014, 20/12/2014). Data Sheet AIREX T92 Easy Processing Structural Foam. Available: http://www.3accorematerials.com/products/airex/airexreg-t92.html

[12] A. Standard, "C393 (2000)," Standard test method for flexural properties of sandwich constructions. ASTM C393-00. ASTM International, Philadelphia, Pa, vol. 19103.

[13] B. Pan, K. Qian, H. Xie, and A. Asundi, "Two-dimensional digital image correlation for in-plane displacement and strain measurement: a review," Measurement science and technology, vol. 20, p. 062001, 2009. 